\title{
Cognitive and behavioural dysfunctions in a patient with progressive supranuclear palsy (PSP)
}

\section{BACKGROUND}

The aim of the case study was to describe the profile of cognitive and emotional functioning of a patient with possible progressive supranuclear palsy (PSP) from a longitudinal perspective.

\section{PARTICIPANTS AND PROCEDURE}

This study involved an 71-year-old male patient diagnosed with PSP, and 9 matched healthy subjects. Neuropsychological examination of the patient was performed twice with a 6-month interval. A set of neuropsychological tests was used to assess both cognition and behaviour

\section{RESULTS}

Neuropsychological assessment revealed executive dysfunction dominance (planning deficits, reduced cognitive flexibility and abstract thinking, impulsiveness), reduced verbal fluency, psychomotor slowness and problems with memory retrieval from the long-term memory storage in contrast to significantly better recognition of the previously learned information. According to emotional functioning, frontal change of personality was observed, with apathy, disinhibition, lack of insights, impulsiveness and "utilization behaviours".

\section{CONCLUSIONS}

The profile of emotional and cognitive impairments met the criteria for dementia. There was a progression of deficits at visit two in comparison to visit one. The longitudinal perspective allowed the dynamics of emotional, cognitive and behavioural changes to be described over time: from depression related to initially preserved criticism of the illness to apathy and emotional blunting and behavioural frontal syndrome connected with the systematic loss of insight.

\section{KEY WORDS}

dysexecutive syndrome; neuropsychological deficits; cognition

ORGANIZATION - 1: Department of Psychiatry, Jagiellonian University Medical College, Krakow, Poland .

2: Department of Neurology, Jagiellonian University Medical College, Krakow, Poland

Authors' Contributions - A: Study design · B: Data collection · C: Statistical analysis · D: Data interpretation ·

E: Manuscript preparation · F: Literature search · G: Funds collection

CORRESPONDing Author - Anna Starowicz-Filip, Ph.D., Department of Psychiatry, Jagiellonian University Medical

College, 21 A Kopernika Str., 31-501 Krakow, Poland, e-mail: starow@poczta.onet.pl 


\section{BACKGROUND}

Progressive supranuclear palsy (PSP), also named Steele-Richardson-Olszewski disease, is a neurodegenerative illness, classified as one of the Parkinson-plus syndromes. The atrophy affects mainly the brainstem, diencephalon, frontal lobes, sometimes the precentral gyrus and the postcentral gyrus, superior cerebellar peduncles and the dentate nucleus (Steele, Richardson, \& Olszewski, 1964; Jelic, Nennesmo, Palhagen, \& Winblad, 2011; Sitburana \& Ondo, 2009; Hauw \& Agid, 2003). The exact etiology of the disease is not known yet but the evidence suggests that it is due to abnormal deposition of tau protein in neuronal tissues (Motyl, 2007). Its prevalence is approximately 5 cases per 100000 (Nath et al., 2001; Bower, Maraganore, McDonnell, \& Rocca, 1997). It starts mostly in the middle or older age (Williams \& Lees, 2009) and the median survival is 6-12 years (Williams \& Lees, 2010). The neurological symptoms of PSP include stiffness, bradykinesia, postural instability with frequent falls, supranuclear gaze palsy in the vertical direction, apraxia of eyelid opening and closing, dysarthria and dysphagia. Cognitive and emotional impairments, as well as personality changes, are also noticed (Houghton \& Litvan, 2007; Burn \& Lees, 2002). In the neuropsychiatric profile of PSP patients apathy is found to be the most common negative symptom (Gerstenecker, Duff, Mast, \& Litvan, 2013; Rittman, Coyle-Gilchrist, \& Rowe, 2016). PSP is often underdiagnosed and must be distinguish from other movement disorders such as Parkinson's disease (PD), multiple system atrophy (MSA), corticobasal degeneration (CBD) and dementia with Lewy bodies (DLB) (Armstrong, 2011). Describing the neuropsychological profile of cognitive impairments of PSP patients could be helpful in the diagnosis. In our case report we describe the cognitive, behavioural and emotional course of a PSP patient. We performed the neuropsychological examination twice, with a 6-months interval between examinations, which gave an opportunity to observe the progress of neuropsychological deficits. To the best of our knowledge there is a lack of PSP case reports showing the cognitive impairments from the longitudinal perspective.

\section{PARTICIPANTS AND PROCEDURE}

A 71-year-old patient with 10 years of formal education, a retired professional turner, was re-admitted to the Department of Neurology with a diagnosis of unspecified parkinsonism and suspected progressive supranuclear palsy. The patient reported symptoms of psychomotor slowness, difficulty in walking, the presence of falling backwards, lower volume of speech and swallowing problems. In terms of cognitive processes, slowness of thought and difficulty of making decisions were observed. The patient denied memory problems. He reported depressed mood, suicidal tendencies and uncontrolled crying which appeared few years ago. In recent MRI of the head leukoaraiosis around the lateral ventricles was observed. In the corona radiata and centrum semiovale white matter, numerous, predominantly small (5 mm), subcortical frontoparietal zones of vascular changes were revealed (Figure 1). The ventricular system was slightly enlarged, reflecting the subcortical brain atrophy (Figure 2). Moderate cortical atrophy of the brain was also revealed. MRI revealed thinning of the head midbrain in the cross-sectional view (Figure 3).

With regards to the control group, 10 potential participants were recruited from Krakow Rehabilitation Center (treated for spinal degeneration) and carefully screened in order to identify persons with no significant health problems such as cognitive impairment, hypertension or neuropsychiatric disorders. At the end of the screening stage, 9 healthy controls (six males, mean age $69.30 \pm 6.52$ years, range 66-74 years, mean years of formal education 10.00 \pm 1.33 ) took part in the study. In order to exclude from the control group subjects with possible cognitive impairment, we only included patients with a Mini Mental State Examination (MMSE) score > $26(M=28.50, S D=0.07$, range 27-29) and with no history of medical or psychological conditions known to be associated with cognitive problems.

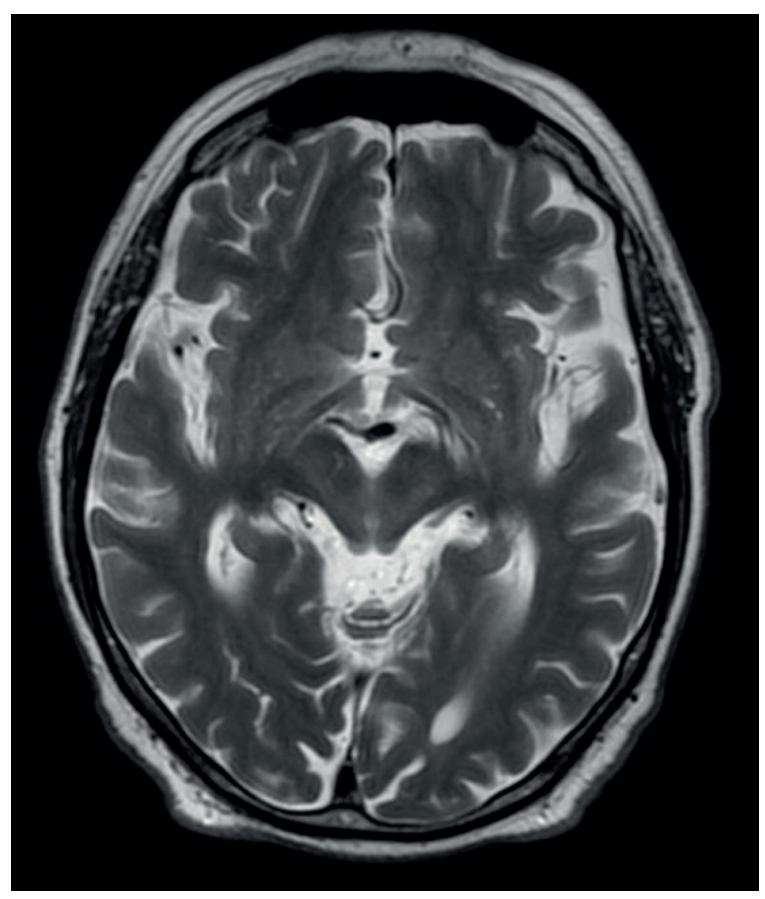

Figure 1. Atrophy of the area of the midbrain - cross section (MRT2 midbrain).
Cognitive and behavioural profile of progressive supranuclear palsy (PSP) 


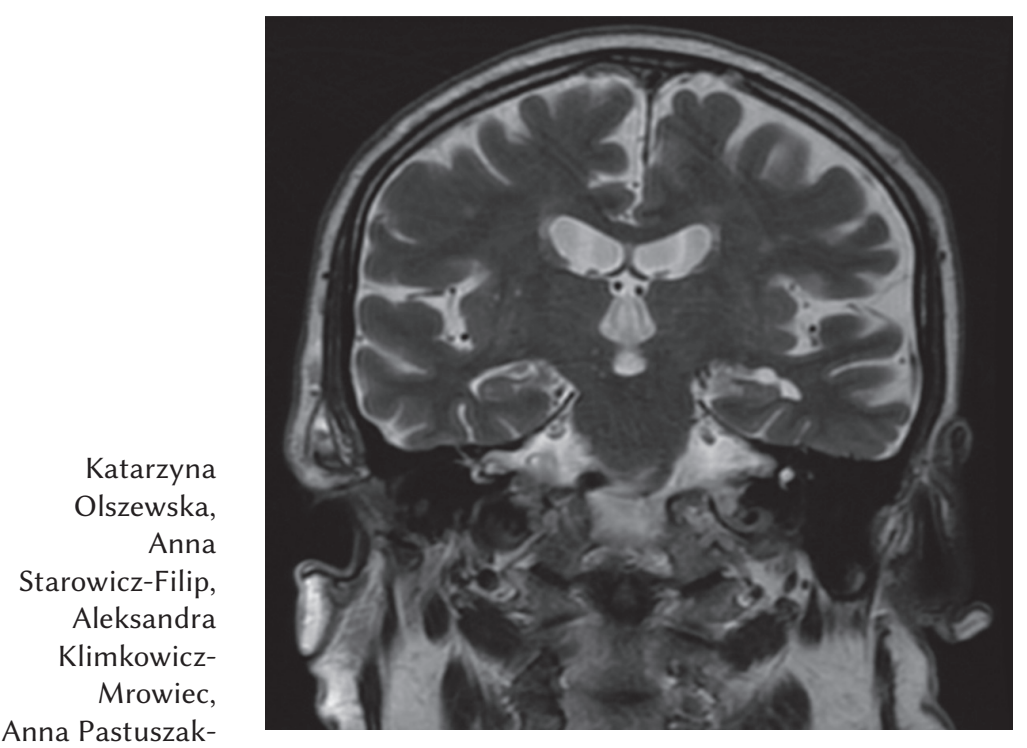

Draxler,

Barbara

Bętkowska-

Korpała

Figure 2. Subcortical brain atrophy (MRI coronal T2 subcortical atrophy).

\section{MEDICAL EXAMINATION}

Electroencephalographic examination showed a record with slight retardation and reduced reactivity of the basic rhythm. The alpha wave range was $8-9 \mathrm{~Hz}$ with amplitude of $40 \mu \mathrm{V}$ in parietal-occipital leads.

Intracranial ultrasound examination showed that all visible vessels were unobstructed with the normal blood velocity.

Ultrasound revealed bilateral patent carotid arteries, IM thickened up to $1.20 \mathrm{~mm}$. Vertebral and carotid arteries were patent bilaterally with symmetric blood flow towards the brain.

Neurological examination showed the presence of hypomimia, lack of vertical eye movement, reduced spontaneous speech with monotonous prosody and dysarthria. The reflexes of the base were disturbed. Muscle tension was increased with symmetrical bradykinesia. There was a resting and position tremor in the upper limbs. The walk was sliding with limited balancing of the upper limbs. Steps were small with "freezing". The patient made the whole body turn, but in an unstable way.

The neurologopedic examination showed phonatory disorders and aphonia. The patient's speech was voiced with correct articulation and understandable. Aprosodia of speech was present because of the whispered speech.

The patient did not respond to levodopa (500 mg daily). He did not have any significant general health comorbidities (e.g. hypertension) at the time of this study.

\section{NEUROPSYCHOLOGICAL EXAMINATION}

The neuropsychological examination was performed twice at a 6-month interval and included observation

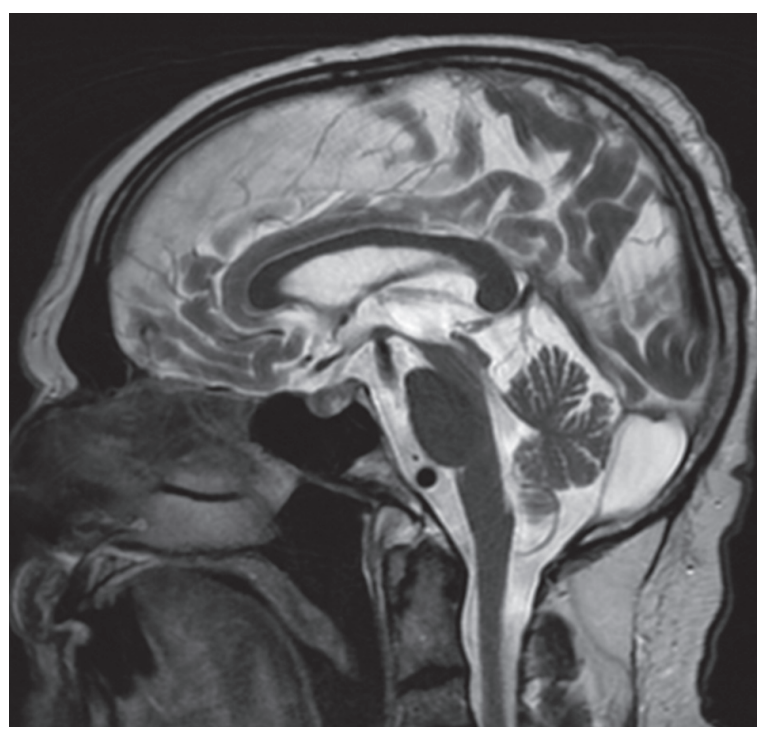

Figure 3. Sagittal projection (MRI sagittal T2 projection).

of the behaviour and an interview with the patient and his wife supplemented with the Dysexecutive Questionnaire (DEX) from the BADS battery (Behavioural Assessment of the Dysexecutive Syndrome) and the Frontal Behaviour Inventory Questionnaire (Kertesz, Davidson, \& Fox, 1997; Pąchalska \& MacQueen, 1998), the Mini Mental State Examination (MMSE; Folstein, Folstein, \& McHuhg, 1975), the Auditory Verbal Learning Test by Luria (AVLT; Łuria, 1976; Taralowska, Florkowski, Orzechowska, Zboralski, \& Gałecki, 2011), Luria's Memory Words Test (LMWT; Luria, 1962; Ardila, 1992), the Weigl Color Form Sorting Test (CFST), the Wisconsin Card Sorting Test (WCST), the Trial Making Test (TMT), the Verbal Fluency Test (VFT) (Piskunowicz, Bieliński, Zgliński, \& Borkowska, 2013), the Frontal Assessment Battery at bedside (FAB), the Clock Drawing Test, a copy of a cube, the experimental task of crossing out letters $\mathrm{E}$ and $\mathrm{R}$, and the Frenchay Aphasia Screening Test (FAST) (Enderby, Wood, Wade, \& Hewer, 1986). The control group was examined once with the same methods.

Descriptive statistical analyses were performed with Statistical Package for the Social Sciences 21 (SPSS 21). Comparisons of the patient's scores with healthy controls' scores were performed by means of a modified $t$-test, according to the procedure described by Crawford, Howell and Garthwaite (1998) and Crawford and Garthwaite (2002) to deal with single cases in cognitive neuropsychology.

In the first place, the patient's scores on the neuropsychological measures from the first examination (T1) were compared to the scores of the healthy control group. Subsequently, in order to show longitudinal changes and to monitor the patient's cognitive functioning over time, his scores from the examination which took place six months later (T2) were compared with the scores of healthy controls. 


\section{RESULTS}

The patient and 9 healthy controls recruited for this study were comparable in terms of both age and level of formal education. Table 1 presents demographic data of the PSP patient and the healthy controls.

The patient's and the healthy controls' scores and the statistical comparisons are shown in Table 2 .

The comparisons between the patient and the control group show that: In the first (T1) and second examination (T2) the patient's scores were significantly worse than the healthy control group's scores on the MMSE measure (T1: $t(9)=15.65, p=.001$; T2: $t(9)=29.07, p<.001)$. The patient obtained significantly worse scores on the LMWT, both in the first examination [T1: third repetition $t(9)=3.75, p=.005$, fourth repetition $t(9)=5.02, p=.001$, fifth repetition $t(9)=10.09, p<.001$, distraction: $t(9)=6.91, p<.001$ and recognition: $t(9)=4.12, p=.003)]$ and in the second examination [T2: first repetition $t(9)=4.71, p=.001$, second repetition $t(9)=3.28, p=.010$, third repetition $t(9)=6.09, p<.001$, fourth repetition $t(9)=5.02$, $p<.001$, fifth repetition $t(9)=7.36, p<.001$, distrac- tion: $t(9)=6.91, p<.001$ and recognition: $t(9)=7.06$, $p<.001)]$. The patient's time of performance in the TMT test was significantly longer than that of the control group [T1: part A time $t(9)=-12.08, p<.001$; part B time $t(9)=-12.55, p<.001$; T2: part A time $t(9)=-36.46, p<.001$; part B time $t(9)=-35.89$, $p<.001]$. The patient made significantly more mistakes in the TMT test in both examinations [T1: part

Table 1

Demographic data

\begin{tabular}{lcccc}
\hline & $\begin{array}{c}\text { PSP } \\
\text { patient }\end{array}$ & $\begin{array}{c}\text { Healthy } \\
\text { controls } \\
(\mathrm{SD}) \\
(n=9)\end{array}$ & $t(9)$ & $p$ \\
& & $69.30(6.52)$ & -.83 & .431 \\
\hline $\begin{array}{l}\text { Age in years } \\
\text { Gender }(\mathrm{M}: \mathrm{F})\end{array}$ & $11: 0$ & $6: 3$ & & \\
$\begin{array}{l}\text { Education in } \\
\text { years }\end{array}$ & 10 & $10(1.33)$ & .00 & 1.00 \\
\hline
\end{tabular}

Cognitive and behavioural profile of progressive supranuclear palsy (PSP)

\section{Table 2}

PSP Patient and control group comparison on general neuropsychological measures separately for the first and the second examination

\begin{tabular}{|c|c|c|c|c|c|c|c|}
\hline Dependent variable & $\begin{array}{c}\text { PSP } \\
\text { patient } \\
\text { T1 }\end{array}$ & $\begin{array}{c}\text { Healthy } \\
\text { controls } \\
(\mathrm{SD}) \\
(n=9)\end{array}$ & $\begin{array}{c}t(9) \\
\mathrm{T} 1\end{array}$ & $\begin{array}{c}p \\
\mathrm{~T} 1\end{array}$ & $\begin{array}{c}\text { PSP } \\
\text { patient } \\
\text { T2 }\end{array}$ & $\begin{array}{c}t(9) \\
\text { T2 }\end{array}$ & $\begin{array}{c}p \\
\mathrm{~T} 2\end{array}$ \\
\hline LMWT / 1 & 4 & $4.60(1.07)$ & 1.77 & .111 & 3 & 4.71 & .001 \\
\hline LMWT / 2 & 6 & $6.40(1.35)$ & 0.94 & .373 & 5 & 3.28 & .010 \\
\hline LMWT / 3 & 6 & $7.60(1.35)$ & 3.75 & .005 & 5 & 6.09 & $<.001$ \\
\hline LMWT / 4 & 6 & $7.90(1.2)$ & 5.02 & .001 & 6 & 5.02 & .001 \\
\hline LMWT / 5 & 5 & $8.70(1.16)$ & 10.09 & $<.001$ & 6 & 7.36 & $<.001$ \\
\hline LMWT / distraction & 4 & $7.60(1.65)$ & 6.91 & $<.001$ & 4 & 6.91 & $<.001$ \\
\hline LMWT / recognition & 8 & $9.40(1.07)$ & 4.12 & .003 & 7 & 7.06 & $<.001$ \\
\hline TMT part A / time & 175 & $70.90(27.25)$ & -12.08 & $<.001$ & 385 & -36.46 & $<.001$ \\
\hline TMT part A / mistakes & 1 & $0.10(0.32)$ & -9.00 & $<.001$ & 0 & 1.00 & .343 \\
\hline TMT part B / time & 330 & $151.50(44.98)$ & -12.55 & $<.001$ & 662 & -35.89 & $<.001$ \\
\hline TMT part B / mistakes & 16 & $0.70(0.67)$ & -71.68 & $<.001$ & 5 & -20.15 & $<.001$ \\
\hline VFT / semantic & 10 & $16.20(4.24)$ & 4.63 & .001 & 9 & 5.37 & $<.001$ \\
\hline VFT / letter & 6 & $11.30(3.47)$ & 4.84 & .001 & 7 & 3.92 & .003 \\
\hline VFT / letter / mistakes & 2 & $0.20(0.42)$ & -13.50 & $<.001$ & 0 & 1.50 & .168 \\
\hline MMSE & 25 & $28.50(0.71)$ & 15.65 & $<.001$ & 22 & 29.07 & $<.001$ \\
\hline CDT & 10 & $9.90(0.32)$ & -1.00 & .343 & 10 & -1.00 & .343 \\
\hline
\end{tabular}

Note. T1 - first neuropsychological assessment: at the beginning of the study; T2 - second neuropsychological assessment: after six months; LMWT - Luria Memory Words Test; TMT - Trial Making Test; VFT - Verbal Fluency Test; MMSE - Mini Mental State Examination Test; CDT - Clock Drawing Test. 
Katarzyna Olszewska, Anna

Starowicz-Filip, Aleksandra

KlimkowiczMrowiec,

Anna PastuszakDraxler, Barbara

BętkowskaKorpała
A number of mistakes $t(9)=-9.00, p<.001$; part $\mathrm{B}$ number of mistakes $t(9)=-71.68, p<.001$; T2: part $\mathrm{A}$ number of mistakes NS; part B number of mistakes $t(9)=-20.15, p<.001]$. The patient scored significantly worse on semantic fluency VFT-semantic [T1: $t(9)=4.63, p=.001$; T2: $t(9)=5.37, p<.001]$; and phonological fluency VFT-letters [T1: $t(9)=4.84, p=.000$; T2: $t(9)=3.92, p=.003$ ]. In other neuropsychological measures administered (CDT, FAST, CFST), the patient's performance did not differ significantly from healthy controls' performance.

In the measures without possibility of comparison to the norms (FBI, FAB, DEX, WCST, a copy of a cube, task of crossing out letters $\mathrm{E}$ and $\mathrm{R}$ ), a descriptive analysis is presented below. We also present the qualitative analysis of performance in the neuropsychological examination.

In the executive measures: in the WCST test the patient was able to finish only one category without the ability of mental switching for another one (the score was impossible to compare with norms). Numerous perseveration errors occurred. Finally, the patient gave up the task due to significant fatigue. Execution of the Frontal Assessment Battery (FAB) at bedside presented a significant problem with the go/no go task, susceptibility to interference, and reaction inhibition problems. The Dysexecutive Questionnaire (DEX) and Frontal Behaviour Inventory Questionnaire (FBI) revealed a decline in criticism, lack of shame and social embarrassment, decreased flexibility in thinking, impulsiveness, "utilization behaviours", problems with abstract thinking, planning and organizing everyday activities and logopenia. The memory functions were relatively well preserved, especially long-term memory.

Language functions and verbal fluency: the Verbal Fluency Test revealed impaired semantic fluency and letter fluency; vulgar words and perseverations appeared. The language functions were preserved, without typical aphasic speech impairments such as problems with understanding or naming (the Frenchay Aphasia Screening Test results), but apraxia of speech was present.

Visuospatial and constructive processes: During the cube copy constructive apraxia was observed. Further praxis examination revealed dynamic dyspraxia (the patient had difficulty with motor planning), and preserved spatial and symbolic (ideomotor) praxis. In the second neuropsychological examination dyspraxia was more visible.

Mental speed: The slowness of performance in the experimental task of crossing out the letters $\mathrm{E}$ and $\mathrm{R}$ (first examination: 3 minutes and 36 seconds, second examination: 3 minutes and 35 seconds) proved psychomotor retardation.

In the behaviour observation psychomotor slowness, difficulty with starting the activities and resting tremors were observed. Bradykinesia and problems with balance were present during walking. Eyes remained fixed in a constant staring upward gaze, depicting supranuclear horizontal and vertical gaze palsies. The facial expression was poor (face dystonia). The speech was dysarthric and aphonic.

In the interview with the subject's wife the following dysexecutive problems were reported: a decline in criticism, lack of shame and social embarrassment, decreased flexibility in thinking, impulsiveness and "utilization behaviours" - strong need for touching objects that were within his reach. There were also problems with abstract thinking, planning and organizing everyday activities. The patient became significantly less talkative (logopenia). Memory functions were relatively well preserved, especially long-term memory. In terms of emotional functioning, the wife reported occurrence of sadness, anxiety and depression, withdrawal from social contact, emotional indifference in some situations and a lack of empathy. Depression was found at the beginning of the illness, while in time more symptoms of apathy appeared.

\section{DISCUSSION}

The described patient presented gait instability, frequent falls, abnormal eye movements and the early onset of subcortical dementia with the frontal-executive syndrome, which strongly suggest PSP as the most likely diagnosis. According to the cognitive and emotional characteristics, executive dysfunction dominance was observed. It manifested with planning deficits, reduced cognitive flexibility and abstract thinking, and increased impulsiveness. Problems in metacontrol of intentional behaviour were present. Frontal lobe paradox was observed with dissociation between knowledge and action. Susceptibility to interference and reaction inhibition problems were also significant. The executive decline in PSP has also been confirmed in other research which showed its impact on quality of life (Pekmezović et al., 2015) and activities of daily living (Litvan \& Kong, 2014). Moreover, reduced verbal fluency, psychomotor slowness and problems with memory retrieval were also present. The deficit of letter fluency was similar to the results of Rittman et al. $(2013,2016)$ and helped us to state that our patient was more likely to have the syndrome of PSP rather than idiopathic PD. The observed level of cognitive functioning can be characterized as frontal-subcortical dementia, described in the literature as one of the most pathognomonic signs of PSP. The research in this field indicates that cognitive impairment develops in almost all patients with PSP, and the characteristic features for subcortical dementia include slowness of information processing and thinking, difficulty in working memory, and attention deficits (especially task switching) (Liberski, Sobów, \& Wszołek, 2005). However, the descrip- 
tion of PSP as a subcortical dementia is incomplete (Ferrara \& Litvan, 2011) as frontal lobe pathology is also present (Paviour, Price, Jahanshahi, Lees, \& Fox, 2006). Patients with PSP exhibit executive dysfunctions manifested by cognitive inflexibility and difficulties with problem solving. Difficulties are also evident in tasks that require abstract thinking (Walsh \& Darby, 2008; Ferrara \& Litvan, 2011).

The memory impairments with a frontal like profile (manifested with bad retrieval but relatively good memory storage and disorganized auditory learning process - with no mnemonic strategy) were relatively small compared to the dysexecutive syndrome. The results of the two memory examinations were comparable after 6 months, without significant progression in memory impairment. This result is consistent with other research, which shows that the functioning of memory in PSP is better than in Parkinson's disease with dementia, dementia with Lewy bodies and Alzheimer's disease (Litvan, 1994; Dubois, Deewer, \& Pillon, 1996; Aarsland et al., 2003). Patients usually perform relatively well on short-term memory tests. Verbal learning tasks show a greater deterioration of recall, with much less disturbed word recognition (Ferrara \& Litvan, 2011).

Our patient manifested speech rather than language problems, which can be defined as apraxia of speech with motor programming problems, articulatory impairments, prosody deficits, rhythm and intonation errors. The patient did not suffer from a language deficiency (such as aphasia), but had difficulty in the production of language in an audible manner. This difficulty was mainly limited to vocal speech, and did not affect sign-language production. Moreover, the patient knew exactly what he wanted to say, but there was a disruption in the part of the brain that sent the signal to the muscle for the specific movement. This symptom has been described in some PSP cases before, especially those with a long follow-up (Kertesz, McMonagle, Blair, Davidson, \& Munoz, 2005). However, some researchers claim that speech deficits in PSP are usually mild and disturbed verbal fluency is the most consistent impairment (Albert, Feldman, \& Willis, 1974; Lange et al., 2003).

The psychiatric symptoms were the early signs of the illness in our patient. Their specificity in our patient supports frontal deficits with depression, emotional lability and in the later course apathy, criticism decline, lack of empathy, emotional blunting and "utilization behaviours”. Psychopathological symptoms characteristic for the frontal lobe syndrome could be observed relatively early in this disease course. Disinhibition is a behavioural symptom observed in PSP that affects $30 \%$ to $50 \%$ of patients (Millar, Griffiths, \& Zermansky, 2006). "Utilization behaviour" is also described, considered to be an extreme form of "environment-dependence syndrome” (Lhermitte, 1983). People with PSP often have preserved insight and are aware of their cognitive problems (Liberski, Sikorska, \& Sobów, 2006), which may cause depression, apathy, aboulia and irritability. Apathy is a major problem in PSP, which is independent from depression and affects approximately $90 \%$ of patients (Ferrara \& Litvan, 2011). Hypochondriacal attitude and psychotic symptoms might also be present, but they are less common (Lauterbach, 2004; Millar et al., 2006). The occurrence of withdrawal from social contact, emotional indifference and the lack of empathy in our patient can be explained in terms of brain atrophy in the frontal lobe (among other brain regions), such deterioration being linked with a lack of empathy and emotional blunting (Steele et al., 1964; Jelic et al., 2011; Hillis, 2014). The diagnosis of PSP is never easy, and there are a few neurodegenerative diseases which should be considered and eliminated (Kertesz, Jesso, Harciarek, Blair, \& McMonagle, 2010). For example, progressive supranuclear palsy (PSP) and corticobasal degeneration (CBD) often clinically overlap. While PSP patients often have severe postural instability at onset, symmetric parkinsonism, vertical present lateralized motor (e.g., parkinsonism, dystonia or myoclonus) and cognitive signs (e.g., ideomotor apraxia, aphasia or alien limb) (Litvan et al., 1999), they were absent in the case of our patient. PSP may resemble DLB, but the occurrence of visual hallucinations, cognitive decline and fluctuating cognition with pronounced variation in attention and alertness may be helpful exclusion criteria of PSP (Liscic, Srulijes, Gröger, Maetzler, \& Berg, 2013). According to our patient, positive psychiatric symptoms, such as hallucinations, were absent. It is evident that PSP is not a purely movement disorder. As a clinical syndrome it encompasses motor, cognitive, behavioural and language deficits that may overlap clinically with frontotemporal dementia (FTD), progressive nonfluent aphasia (PNFA) and to a small extent with semantic dementia (SD). What is more, although FTD and PNFA begin as cortical syndromes, they can evolve into CBD-like or PSP-like movement disorder. Significant differences still remain, however, between CBD, PSP and FTD. First, these three disorders have distinct anatomical patterns of degeneration: PSP is associated with extensive pathological changes in the cerebellum and pons, whereas CBD, PNFA and FTD generally spare this region. In FTD the most prominent atrophy is generally frontal, temporal or both. FTD is differentiable from CBD and PSP when behavioural impairments are dominant and the patient shows relatively spared language and memory function (Sha, Hou, Viskontas, \& Miller, 2007). According to our patient, the general pattern of deficits was reverse, with dominant cognitive problems and coexisting emotional impairments. However, recent research has shown the existence of a spectrum of cognitive and behavioural features in PSP which overlap with behavioural variant FTD, e.g. disinhibi-
Cognitive and behavioural profile of progressive supranuclear palsy (PSP) 
Katarzyna Olszewska, Anna

Starowicz-Filip, Aleksandra

KlimkowiczMrowiec,

Anna PastuszakDraxler, Barbara BętkowskaKorpała tion, apathy, and executive impairments, and these disturbance may evolve over time (Kobylecki et al., 2015). The overlap of PSP and PNFA has recently been reported, too. It has been proposed that PNFA, and in particular the presence of progressive apraxia of speech (AOS), predicts tau histopathologies, including PSP. Rohrer (Rohrer et al., 2010) writes that some patients with PNFA may subsequently develop characteristic features of PSP including a typical oculomotor palsy. The neuropsychological profile in these cases was similar to other patients with PNFA, but with more marked reduction in propositional speech, fewer speech errors, but more severely associated deficits of episodic memory and praxis (Rohrer et al., 2010). This pattern of clinical and cognitive deficits in PSP-PNFA is consistent with the greater involvement of prefrontal areas and less marked involvement of perisylvian areas. The patient with progressive speech apraxia and early marked impoverishment of propositional speech without prominent speech errors (present in our patient) should be observed for development of the PSP syndrome (Rohrer et al., 2010).

To sum up, according to the literature the described patient did not present any other symptoms characteristic for these neurodegenerative diseases.

To our knowledge, no effective treatment is available for PSP. A few studies have pointed towards the use of rivastigmine for PSP cognitive impairments (Nijboer \& Dautzenberg, 2009). Taking into account the limitations of managing cognitive and behavioural symptoms in PSP, non-pharmacological interventions are suggested as the first line of treatment, including education and support for caregivers (Rittman et al., 2016). The role of a multispecialty treatment team as well as family support is crucial in the management of this complex disease. We proposed neuropsychological rehabilitation to this patient. There were tasks for attention, executive functions and memory exercises which the patient performed every day together with his wife. He also had regular exercises with a speech therapist. Interventions also included communication skills, education for the patient and his caregivers, exercises, and caregiver coping skills and guidance. In Poland it is still a rare and unpopular form of help for PSP patients, but we believe that it not only helps slow down the progression of cognitive decline but also gives a sense of control over the illness situation, which in consequence may reduce the depressive symptoms. Although the interventions did not crucially improve scores on cognitive tests, thanks to neurorehabilitation and a better understanding of the symptoms of the disease, the quality of life of the patient and caregivers has improved.

What is notable in this case is the presence of PSP symptoms for 12 years while the average illness duration is 5-12 years (Liberski et al., 2006; Williams
\& Lees, 2009). We suppose that, among other factors, the intense rehabilitation and family support may explain such a long period of survival. The patient is still alive, so PSP may be confirmed at autopsy in the future.

Strengths of the present study are the longitudinal approach and the implementation of a modified $t$-test, specifically designed to deal with single case studies.

\section{CONCLUSIONS}

The longitudinal perspective of the patient's neuropsychological examination allowed us to describe the dynamics of behavioural changes over time.

The neuropsychological progression of the illness included emotional and behavioural changes: from depression (related to initially preserved criticism of the illness), to emotional blunting, apathy and behavioural frontal syndrome (connected with the systematic loss of insight).

The profile of cognitive changes confirmed progressive subcortical-frontal neurodegeneration with increasing slowness and dysexecutive syndrome in contrast to memory, as well as visuospatial functions relatively well preserved.

The executive impairment caused the patient's growing dependence on the relatives and the inability to use the preserved cognitive abilities in everyday life. In consequence the patient needs total care and help from his family.

\section{RefERENCES}

Ardila, A. (1992). Luria's Approach to neuropsychological assessment. International Journal of Neuroscience, 66, 35-43.

Armstrong, R. A. (2011). Visual signs and symptoms of progressive supranuclear palsy. Clinical and Experimental Optometry, 94, 150-160. https://doi.org/ 10.1111/j.1444-0938.2010.00504.x

Aarsland, D., Litvan, I., Salmon, D., Galasko, D., Wentzel-Larsen, T., \& Larsen, J. P. (2003). Performance on the dementia rating scale in Parkinson's disease with dementia and dementia with Lewy bodies: comparison with progressive supranuclear palsy and Alzheimer's disease. Journal of Neurology, Neurosurgery, and Psychiatry, 74, 1215-1220. https://doi.org/10.1136/jnnp.74.9.1215

Albert, M. I., Feldman, R. G., \& Willis, A. L. (1974). The "subcortical dementia" of progressive supranuclear palsy. Journal of Neurology, Neurosurgery, and Psychiatry, 76, 420-422.

Bower, J. H., Maraganore, D. M., McDonnell, S. K., \& Rocca, W. A. (1997). Incidence of progressive supranuclear palsy and multiple system atrophy in 
Olmsted County, Minnesota, 1976 to 1990. Neurology, 49, 1284-1288.

Burn, D. J., \& Lees, A. J. (2002). Progressive supranuclear palsy: where are we now? The Lancet Neurology, 1, 359-369.

Crawford, J. R., \& Garthwaite, P. H. (2002). Investigation of the single case in neuropsychology: confidence limits on the abnormality of test scores and test score differences. Neuropsychologia, 40, 1196-1208.

Crawford, J. R., Howell, D. C., \& Garthwaite, P. H. (1998). Payne and Jones Revisited: Estimating the Abnormality of Test Score Differences Using a Modified Paired Samples t Test. Journal of Clinical and Experimental Neuropsychology, 20, 898-905.

Dubois, B., Deewer, B., \& Pillon, B. (1996). The cognitive syndrome of progressive palsy. Advances in Neurology, 69, 399-403. https://doi.org/10.1016/j. parkreldis.2016.07.007

Enderby, P. M., Wood, V. A., Wade, D. T., \& Hewer, R. L. (1986). The Frenchay Aphasia Screening Test: a short, simple test for aphasia appropriate for nonspecialists. International Rehabilitation Medicine, 8, 166-170.

Ferrara, J. M., \& Litvan, I. (2011). Kobieta z zaburzeniami chodu i trudnościami w czytaniu [A woman with a gait disorder and reading difficulties]. In S. Gauthier \& P. Rossa-Neto (Eds.), P. P. Liberski \& T. Sobów (Polish Eds.), Demencja. Trafna diagnoza [Dementia. Accurate diagnosis] (pp. 233-242). Warszawa: PZWL.

Folstein, M. F., Folstein, S. E., \& McHugh, P. R. (1975). "Mini-mental state". A practical method for grading the cognitive state of patients for the clinician. Journal of Psychiatric Research, 12, 189-198.

Gerstenecker, A., Duff, K., Mast, B., \& Litvan, I. (2013). Behavioral Abnormalities in Progressive Supranuclear Palsy. Psychiatry Research, 210, 1205-1210. https://doi.org/10.1016/j.psychres.2013.08.045

Hauw, J. J., \& Agid Y. (2003). Progressive supranuclear palsy (PSP) or Steele-Richardson-Olszewski disease. In D. W. Dickson (Ed.). Neurodegeneration: The molecular pathology of dementia and movement dis orders (pp. 103-114). Basel: ISN Neuropath Press.

Hillis, A. E. (2014). Inability to empathize: brain lesions that disrupt sharing and understanding another's emotions. Brain, 137, 981-997. https://doi. org/10.1093/brain/awt317

Houghton, D. J., \& Litvan I. (2007). Unraveling progressive supranuclear palsy: from the bedside back to the bench. Parkinsonism \& Related Disorders, 13, S341-S346. https://doi.org/10.1016/S13538020(08)70028-2

Jelic, V., Nennesmo, I., Palhagen, S. E., \& Winblad B. (2011). Najpierw upadki, potem zapominanie [First falls, then forgetfulness]. In S. Gauthier \& P. Rossa-Neto (Eds.), P. P. Liberski \& T. Sobów (Polish Eds.), Demencja. Trafna diagnoza [Dementia. Accurate diagnosis] (pp. 259-264). Warszawa: PZWL.
Kertesz, A., Davidson, W., \& Fox, H. (1997). Frontal Behavioral Inventory: Diagnostic criteria for frontal lobe dementia. Canadian Journal of Neurological Science, 24, 29-36.

Kertesz, A., McMonagle, P., Blair, M., Davidson, W., \& Munoz, D. G. (2005). The evolution and pathology of frontotemporal dementia. Brain, 128, 19962005. https://doi.org/10.1093/brain/awh598

Kertesz, A., Jesso, S., Harciarek, M., Blair, M., \& McMonagle, P. (2010) What Is Semantic Dementia? A Cohort Study of Diagnostic Features and Clinical Boundaries. Archives of Neurology, 67, 483-489.

Kobylecki, C., Jones, M., Thompson, J. C., Richardson, A. M., Neary, D., Mann, D. M., Snowden, J. S., \& Gerhard, A. (2015). Cognitive-behavioural features of progressive supranuclear palsy syndrome overlap with frontotemporal dementia. Journal of Neurology, 262, 916-22. https://doi.org/10.1007/ s00415-015-7657-z

Lange, K. W., Tucha, O., Alders, G. L., Preier, M., Csoti, I., Merz, B., Mark, G., Herting, B., Fornadi, F., Reichmann, H., Vieregge, P., Reiners, K., Becker, G., \& Naumann, M. (2003). Differentiation in parkinsonian syndromes according to differences in executive functions. Journal of Neural Transmission, 110, 983-995. https://doi.org/10.1007/s00702-0030011-0

Lauterbach, E. C. (2004). The neuropsychiatry of Parkinson's disease and related disorders. Psychiatric Clinics of North America, 27, 801-825.

Lhermitte, F. (1983). Utilization behavior and its relation to lesions of the frontal lobes. Brain, 106, 237-255.

Liberski, P. P., Sobów, T., \& Wszołek, Z. K. (2005). Postępujące zwyrodnienie nadjądrowe [Progressive supranuclear degeneration]. In P. P. Liberski \& Z. K. Wszołek (Eds.), Otepienia czołowo-skroniowe [Frontotemporal dementia] (pp. 155-172). Lublin: Wydawnictwo Czelej.

Liberski, P. P., Sikorska, B., \& Sobów T. (2006). Otępienie $\mathrm{w}$ atypowych postaciach parkinsonizmu [Dementia in atypical forms of parkinsonism]. In T. Sobów \& J. Sławek (Eds.), Zaburzenia poznawcze i psychiczne w chorobie Parkinsona i w innych zespotach parkinsonowskich [Cognitive and mental disorders in Parkinson's disease and other parkinsonian syndromes] (pp. 113-126). Wrocław: Wydawnictwo Continuo.

Liscic, R. M., Srulijes, K., Gröger, A., Maetzler, W., \& Berg, D. (2013). Differentiation of Progressive Supranuclear Palsy: clinical, imaging and laboratory tools. Acta Neurologica Scandinavica, 2, 1-9. https://doi.org/10.1111/ane.12067

Litvan, I. (1994). Cognitive disturbances in progressive supranuclear palsy. Journal of Neural Transmission, 42, 69-78.

Litvan, I., \& Kong, M. (2014). Rate of decline in progressive supranuclear palsy. Movement Disorders, 29, 463-468. https://doi.org/10.1002/mds.25843
Cognitive and behavioural profile of progressive supranuclear palsy (PSP) 
Litvan, I., Grimes, D. A., Lang, A. E., Jankovic, J., McKee, A., Verny, M., Jellinger, K., Chaudhuri, K. R., \& Pearce, R. K. (1999). Clinical features differentiating patients with postmortem confirmed progressive supranuclear palsy and corticobasal degeneration. Journal of Neurology, 246, 1-5.

Luria, A. R. (1962). Higher Cortical Functions in Man. New York: Basic Books.

Łuria, A. (1976). Neuropsychologia [Neuropsychology]. Warszawa: PZWL.

Katarzyna

Olszewska, Anna

Starowicz-Filip,

Aleksandra

KlimkowiczMrowiec,

Anna Pastuszak-

Draxler,

Barbara

Bętkowska-

Korpała

Millar, D., Griffiths, P., \& Zermansky, A. J. (2006). Characterising behavioral and cognitive dysexsy. Movement Disorders, 21, 199-207. https://doi. org/10.1002/mds.20707

Motyl, R. (2007). Otępienie - kryteria diagnostyczne [Dementia - diagnostic criteria]. Polski Przeglad Neurologiczny, 3, 43-60.

Nath, U., Ben-Shlomo, Y., Thomson, R. G., Morris, H. R., Wood, H. R., Lees, A. J., \& Burn, J. (2001). The prevalence of progressive supranuclear palsy (Steeleecutive changes in progressive supranuclear palRichardson-Olszewski syndrome) in the UK. Brain, 124, 1438-1449.

Nijboer, H., \& Dautzenberg, P. L. (2009). Progressive supranuclear palsy: Acetylcholineeserase-inhibitor a possible therapy. Tijdschrift voor Gerontologie en Geriatrie, 40, 133-137.

Paviour, D. C., Price, S. L., Jahanshahi M., Lees, A. J., \& Fox, N. C. (2006). Longitudinal MRI in progressive supranuclear palsy and multiple system atrophy: rates and regions of atrophy. Brain, 129, 1040-1049. https://doi.org/10.1093/brain/awl021

Pąchalska, M., \& MacQueen, B. D. (1998). Kwestionariusz Zachowań Osoby z Zespotem Czołowym. Autoryzowany przekład z języka angielskiego: Frontal Behavioral Inventory (Kertesz i wsp., 1997) [Frontal Behavioural Inventory. Authorized translation from English (Kertesz et al., 1997)]. Kraków: Fundacja na Rzecz Osób z Dysfunkcjami Mózgu.

Pekmezović, T., Ječmenica-Lukić, M., Petrović, I., Špica, V., Tomić, A., \& Kostić, V. (2015). Quality of life in patients with progressive supranuclear palsy: oneyear follow-up. Journal of Neurology, 262, 20422048. https://doi.org/10.1007/s00415-015-7815-3

Piskunowicz, M., Bieliński, M., Zgliński, A., \& Borkowska, A. (2013). Testy fluencji słownej - zastosowanie $\mathrm{w}$ diagnostyce neuropsychologicznej [Verbal fluency tests - application in neuropsychological assessment]. Psychiatria Polska, 47, 475-485.

Rittman, T., Coyle-Gilchrist, I. T., \& Rowe, J. B. (2016). Managing cognition in progressive supranuclear palsy. Neurodegenerative Disease Management, 6, 499-508. http://doi.org/10.2217/nmt-2016-0027

Rittman, T., Ghosh, B. C., McColgan, P., Breen, D. P., Evans, J., Williams-Gray, C. H., Barker, R. A., \& Rowe, J. B. (2013). The Addenbrooke's Cognitive Examination for the differential diagnosis and longitudinal assessment of patients with par- kinsonian disorders. Journal of Neurology, Neurosurgery, and Psychiatry, 84, 544-551. https://doi. org/10.1136/jnnp-2012-303618

Rohrer, J. D., Paviour, D., Bronstein, A. M., O’Sullivan, S. S., Lees, A., \& Warren, J. D. (2010). Progressive supranuclear palsy syndrome presenting as progressive nonfluent aphasia: a neuropsychological and neuroimaging analysis. Movement Disorders, 30, 179-188. https://doi.org/10.1002/ mds.22946

Sha, S. J., Hou, C., Viskontas, I. V., \& Miller, B. L. (2007). Are frontotemporal lobar degeneration, progressive supranuclear palsy and corticobasal degeneration distinct diseases? Nature Clinical Practice Neurology, 2, 658-665. https://doi.org/10.1038/ncpneuro0357

Sitburana, O., \& Ondo W. G. (2009). Brain magnetic imaging (MRI) in parkinsonian disorders. Parkinsonism \& Related Disorders, 15, 165-174. https:// doi.org/10.1016/j.parkreldis.2008.04.033

Steele, J. C., Richardson, J. C., \& Olszewski, J. (1964). Progressive supranuclear palsy. A heterogeneous degeneration involving the brain stem, basal ganglia and cerebellum with vertical gaze and pseudobulbar palsy, nuchal dystonia and dementia. Archives of Neurology, 10, 333-359. https://doi. org/10.1055/s-0034-1377058

Talarowska, M., Florkowski, A., Orzechowska, A., Zboralski, A., \& Gałecki, P. (2011). Auditory-verbal learning test by Łuria in the examination of psychiatric patients. Polski Merkuriusz Lekarski, 31, 41-44.

Walsh, K., \& Darby, D. (2008). Ptaty czotowe [Frontal lobes]. In K. Walsh \& D. Darby (Eds.), Neuropsychologia kliniczna Walsha [Walsh's Neuropsychology: A Clinical Approach] (pp. 124-181). Gdańsk: Wydawnictwo GWP.

Williams, D. R., \& Lees, A. J. (2009). Progressive supranuclear palsy: clinicopathological concepts and diagnostic challenges. Lancet Neurology, 8, 270-279. https://doi.org/10.1016/S14744422(09)70042-0

Williams, D. R., \& Lees A. J. (2010). What features improve the accuracy of the clinical diagnosis of progressive supranuclear palsy-parkinsonism (PSP-P)? Movement Disorders, 25, 357-362. https:// doi.org/10.1002/mds.22977 